26 Payne VG Morrow JRJ. Exercise and VO2 max in children: a meta-analysis. Res Q Exerc Sport 1993;64:305-13.

27 Shvartz E, Reibold RC. Aerobic fitness norms for males and females aged 6 to 75 years: a review. Aviat Space Environ Med 1990;61: $3-11$.

28 Takken T, Hemel A, Van der Net J, Helders PJM. Aerobic fitness in children with juvenile idiopathic arthritis: a systematic review. J Rheumatol 2002;29:2643-7.

29 Alexander GJ, Hortas C, Bacon PA. Bed rest, activity and the inflammation of rheumatoid arthritis. Br J Rheumatol 1983;22:134-40.
30 Klepper SE. Effects of an eight-week physical conditioning program on disease signs and symptoms in children with chronic arthritis. Arthritis Care Res 1999; 12:52-60.

31 Kirchheimer JC, Wanivenhaus A, Engel A. Does sport negatively influence joint scores in patients with juvenile rheumatoid arthritis. An 8-year prospective study. Rheumatol Int 1993;12:239-42.

32 Shephard RJ, Shek PN. Autoimmune disorders, physical activity, and training, with particular reference to rheumatoid arthritis. Exerc Immunol Rev 1997;3:53-67.

33 Mackinnon LT. Chronic exercise training effects on immune function. Med Sci Sports Exerc 2000;32:S369-76.

\title{
$\mathrm{ECHO}$
}

\section{Intra-articular steroids can control JIA}

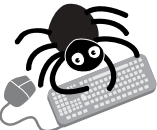

Please visit the Annals of the Rheumatic

Diseases website [www.annrheumdis com] for link to these full articles. $\sim^{j}$ orticosteroid (CS) injection into affected joints is a safe and effective treatment for juvenile idiopathic arthritis (JIA), according to one review. Much of the supporting evidence comes from uncontrolled studies, but its sheer volume attests to the treatment's effectiveness.

The method is used most for oligoarticular and polyarticular JIA, with early injection in the oligoarticular form-without awaiting the outcome of NSAIDs treatment - to gain control and hasten return to normal activity. This avoids joint contractures and unequal leg lengths developing while also avoiding use of systemic CSs.

RCTs and clinical evidence have shown that triamcinolone hexacetonide is the best to use, so its present unavailability is regrettable. UK practice is to inject $1 \mathrm{mg} / \mathrm{kg}$ into large joints, $0.5 \mathrm{mg} / \mathrm{kg}$ into small joints, and $0.6-2 \mathrm{mg} /$ joint into the hands and feet.

One RCT in children has suggested 246/300 triamcinolone hexacetonide injections produced complete resolution in a cohort including all JIA subtypes. In another study of nearly 1500 injections in almost 200 children median length of improvement with triamcinolone hexacetonide was 74 weeks. Best results occurred after the first injection.

The real value of the treatment is obscured in most published studies, because of confusion about JIA subtypes and differing definitions of improvement and length of follow up, not to mention a non-uniform approach to how the injection is given, the precise method, and the recovery schedule. Subcutaneous atrophy is the most well known side effect according to clinical experience. However, true assessment of outcome, CS joint versus systemic injection, or whether treatment modifies JIA await future RCTs.

A Archives of Disease in Childhood 2003;88:192-196.

\section{. . so can methotrexate}

M ethotrexate is invaluable for treating JIA, and its use should be continued, according to another review in the same series. The benefit that children derive outweighs the lack of evidence based RCTs, though these are needed to confirm long term effectiveness and safety.

There has been too little recognition of the transforming effect of methotrexate in one of the commonest chronic childhood disorders. In the UK, for example, it is not licensed for use in JIA. Elsewhere it is the first line treatment for polyarticular JIA, with or without steroids.

Just two short term RCTs have been done in children: one over a decade ago, showing significant clinical improvement in severe JIA, and the other more recently, confirming benefit for extended oligoarticular JIA. But a wealth of qualitative evidence exists from years of clinical use.

Modern treatment aims at securing early control of the disease and preventing joint damage, to maintain function and normal lifestyle. With standard treatment of weekly oral methotrexate $10-15 \mathrm{mg} / \mathrm{m}^{2} 60-75 \%$ of recipients experience significant benefit after $4-6$ months. Doses up to $20-25 \mathrm{mg} / \mathrm{m}^{2}$ by injection can be used without apparent harm.

Monitoring treatment to ensure optimum benefit and safety is an issue for children, their parents, and their health carers; all need to be educated accordingly. Side effects seem to be low, but routine monitoring is required to detect altered liver function or blood profile or a rash, mouth ulcers, or breathing difficulties or cough. All signal a need to interrupt treatment until these are resolved.

A Archives of Disease in Childhood 2003;88:197-200. 